\title{
CONSTRUÇÃO DE PROJETO EAD COM FOCO NA METODOLOGIA DA PROBLEMATIZAÇÃO: O CASO DA FACULDADE CESUSC
}

\author{
FLORIANÓPOLIS/SC MAIO/2018
}

\author{
Emerson Correia da Silva - CESUSC - emerson.silva@cesusc.edu.br \\ Fernando Ramos Lengler - CESUSC - fernandolengler@gmail.com \\ Evelyn Henrique Silva - CESUSC - evelyn.henrique@cesusc.edu.br \\ Matheus Moreira Moraes - CESUSC - matheus.moraes@cesusc.edu.br
}

Tipo: Relato de Experiência Inovadora (EI)

Categoria: Métodos e Tecnologias

Setor Educacional: EDUCAÇÃO SUPERIOR

\begin{abstract}
RESUMO
Relatamos neste texto a Experiência Inovadora da Construção de Projeto EAD com base na metodologia da problematização, da Faculdade Cesusc em Florianópolis. O objetivo principal do texto é relatar a experiência inovadora empreendida na Faculdade Cesusc e demonstrar os aspectos de sua aplicação prática. Ressalta-se como ponto de inovação o próprio uso da Metodologia da Problematização com o Arco de Maguerez em toda a estrutura de EAD da instituição, bem como a primeira a ser feita como guia metodológica para um curso tecnólogo integralmente. Para a realização deste texto utilizamos a metodologia descritiva, com base nos documentos constitutivos do projeto, principalmente Plano de Gestão EAD e o Projeto Pedagógico do Curso Superior de Tecnologia em Gestão Comercial, primeiro curso na modalidade EAD da Instituição relatada. Também foram utilizadas como fontes as atas, fotografias e notícias relativas ao projeto. Como resultados destacamos o caráter autônomo e experimental do projeto e sua execução. A metodologia da problematização é desenvolvida com o intuito de conectar estudantes e professores com as realidades de seus entornos de atuação, bem como com a noção de resolução de problemas reais e situações profissionais aplicadas. Do mesmo modo, pesquisas e teorias são pensadas enquanto suporte de apoio vivo para pensar as diferentes realidades e solucionar problemas.
\end{abstract}

Palavras-chave: Metodologia EAD; Metodologia da Problematização; Arco de Maguerez; 


\section{Introdução}

Relatamos neste texto a Experiência Inovadora da Construção de Projeto EAD com base na metodologia da problematização, da Faculdade Cesusc em Florianópolis.

O objetivo principal deste texto busca relatar a experiência inovadora empreendida na Faculdade Cesusc e demonstrar os aspectos de sua aplicação prática. Ressalta-se como ponto de inovação o próprio uso da Metodologia da Problematização com o Arco de Maguerez em toda a estrutura de EAD da instituição, bem como a primeira experiência a ser feita como guia metodológica para um curso tecnólogo integralmente. Para a realização deste texto utilizamos a metodologia descritiva, com base nos documentos constitutivos do projeto, principalmente Plano de Gestão EAD e o Projeto Pedagógico do Curso Superior de Tecnologia (CST) em Gestão Comercial, primeiro curso na modalidade EAD da Instituição relatada.

Também foram utilizadas como fontes as atas, fotografias e notícias relativas ao projeto. Como resultados destacamos o caráter autônomo e experimental do projeto e sua execução. A metodologia da problematização é desenvolvida com o intuito de conectar estudantes e professores com as realidades de seus entornos de atuação, bem como com a noção de resolução de problemas reais e situações profissionais aplicadas. Do mesmo modo, pesquisas e teorias são pensadas enquanto suporte de apoio vivo para pensar as diferentes realidades e solucionar problemas.

\section{Objetivos}

\section{Objetivo Geral}

O objetivo principal deste texto busca relatar a Experiência Inovadora da Construção de Projeto EAD com base na metodologia da problematização, da Faculdade Cesusc em Florianópolis.

\section{Objetivo Específico}

Demonstrar os aspectos da aplicação prática da metodologia da problematização em um curso de Gestão Comercial na modalidade EAD.

Afirmar o caráter inovador da experiência no campo da Educação a Distância no Brasil, com foco na metodologia escolhida e em sua aplicação focada na identidade docente.

\section{Referencial teórico}


Para este texto tomamos como base os textos de Berbel no que diz respeito ao autor Charles Maguerez e a Metodologia da Problematização e o Método do Arco, suas implicações com a realidade brasileira.

\section{Procedimentos metodológicos}

Para a realização deste texto utilizamos a metodologia descritiva, com base nos documentos constitutivos do projeto, principalmente o Plano de Gestão EAD (2015) e o Projeto Pedagógico do CST em Gestão Comercial (versão atualizada 2017), primeiro curso na modalidade EAD da Instituição relatada. Além dos documentos institucionais citados foram usados, para retomar esta história, atas e notícias, além de material bibliográfico sobre Charles Maguerez.

\section{Apresentação e discussão dos resultados}

\section{Contextualização}

A Faculdade Cesusc vinha de experiências na oferta de cursos e atividades na modalidade a distância desde o ano de 2009, perfazendo 9 (nove) anos de experiência, na forma de Cursos livres, disciplinas de TCC e capacitação interna de pessoal. Essa experiência iniciou-se com a criação do Ambiente Virtual de Aprendizagem Cesusc, implantado com base no Sistema Moodle.

A ideia de oferecer cursos de graduação e pós-graduação era presente, mas a instituição vinha de tentativas de projetos fracassadas, e na região vinha crescendo muito o número de instituições que operam na modalidade a distância. O próprio curso de Administração da Faculdade vinha sentindo uma perda em seu número de estudantes e isso era computado ao aumento da concorrência.

Outro ponto importante era a resistência do corpo de alunos e docente em torno da EAD. A faculdade recebia muitos alunos transferidos de Faculdades EAD e estes alunos vinham com muita rejeição à EAD implantado nos $20 \%$ da carga horária de cursos presenciais. Essas informações repercutiam nos professores que acabaram criando uma imagem negativa da $E A D$, devido à concorrência que estava presente e às más impressões dos alunos que chegavam.

No início de 2014 foram iniciadas as primeiras reuniões para estruturar a ideia do projeto com um entendimento inicial de problema a partir destas três frentes:

- a) necessidade da instituição recuperar sua força tecnológica e inovadora; 
- b) criar uma resposta válida para se posicionar com segurança frente às instituições que chegavam, a isso se inclui grandes grupos internacionais e de tecnologia - calculando também o que seria mais viável em torno de parcerias; e

- c) criar uma cultura propícia para a inovação tecnológica de estudos e mostrar que EAD poderia ser um caminho de estudos que garantisse sucesso de aprendizagem e na vida dos estudantes.

Destas premissas o projeto de Educação a Distância da Faculdade Cesusc teve início em 2014.

Entre os estudos e debates a opção foi por:

Investir esforços em criar uma proposta de EAD inovadora e que dialogasse com seu tempo e comunidade, assim o Arco de Maguerez surgiu como opção realista;

Ter o foco na identidade docente, na experiência e formação do corpo do professores da instituição, e com isso produzir internamente todos os materiais didáticos e ser responsável por todas interações de aprendizado;

Atuar na construção de uma imagem sólida de qualidade em EAD a partir dos cursos e materiais produzidos com a mesma qualidade que os cursos presenciais eram oferecidos.

\section{Metodologia da Problematização}

A Metodologia da Problematização com o Arco de Maguerez foi desenvolvida por Charles Maguerez e descrita por Bordenave e Pereira (1977), sendo aplicada em cursos presenciais e a distância nas últimas décadas no Brasil.

Charles Maguerez nasceu na Bretanha, na década de 1930, oeste da França, atuou na Marinha Mercante após a Segunda Guerra. Foi diplomado pelo Instituto Nacional de Estudos do Trabalho e da Orientação Profissional (Paris). Em 1954 casa-se, e tem contato com intelectuais de esquerda, a "gauche - caviar". A família de sua esposa era originária de Paris. O seu sogro era professor de filosofia e comunista.

Neste período atuou como selecionador e orientador de agricultores para enviá-los a centros de formação de operários. Com os resultados devastadores da Guerra, havia restado pouca mão de obra qualificada e muito trabalho de reconstrução a fazer.

Maguerez passa a ter contato com técnicas de fábricas de automóveis e armas americanas, que no período da Segunda Guerra tinham desenvolvido programas de treinamentos para mulheres aprenderem o trabalho fabril, enquanto os homens estavam em combate. Destas experiências, as empresas privadas francesas e norte-americanas utilizavam métodos desenvolvidos nos EUA com grande relevância.

Em 1959, Maguerez é convidado a trabalhar no Marrocos, com salário 3 vezes maior do 
que recebia na França. Deste período em diante o Método do Arco começa a ser aprimorado, e Maguerez leva a frente a ideia de ensinar operários, agricultores, beduínos a realizarem trabalhos complexos em pouco tempo de aprendizado. Suas ideias passaram por momentos de grande aceitação entre os líderes dos países que passou, até por momentos de questionamento e rejeição por seu caráter emancipatório perigoso.

Outro ponto importante a se ressaltar é o fato de que Maguerez tivesse pouca relevância em termos do campo educacional brasileiro, até ter seu método descrito por Bordenave e Pereira (1977). Teve maior repercussão em espaços de educação agrícola ou empresarial. Também ressalta-se a grande proximidade entre 0 autor $e$ os conhecimentos de Paulo Freire e mesmo de Problem Based Learning. O que neste espaço não debateremos, mas demonstra de alguma forma o pensamento de uma época e respostas parecidas em diferentes lugares do mundo, como acontece no conceito de circularidade social/de saberes como descreveram Bakhtin (1895-1975) e Ginzburg (1939).

\section{Metodologia do Arco e a Faculdade Cesusc}

Na Faculdade Cesusc a metodologia da problematização com o Arco de Maguerez é tomada como referência base, nas suas leituras mais contemporâneas e respeitando as necessidades de aplicação e adaptação, as questões envolvendo o trabalho docente. $O$ foco está na contribuição e reflexão coletiva dos problemas, os estudos e pesquisas teóricas, e a aplicação e a difusão dos conhecimentos produzidos no decorrer dos estudos.

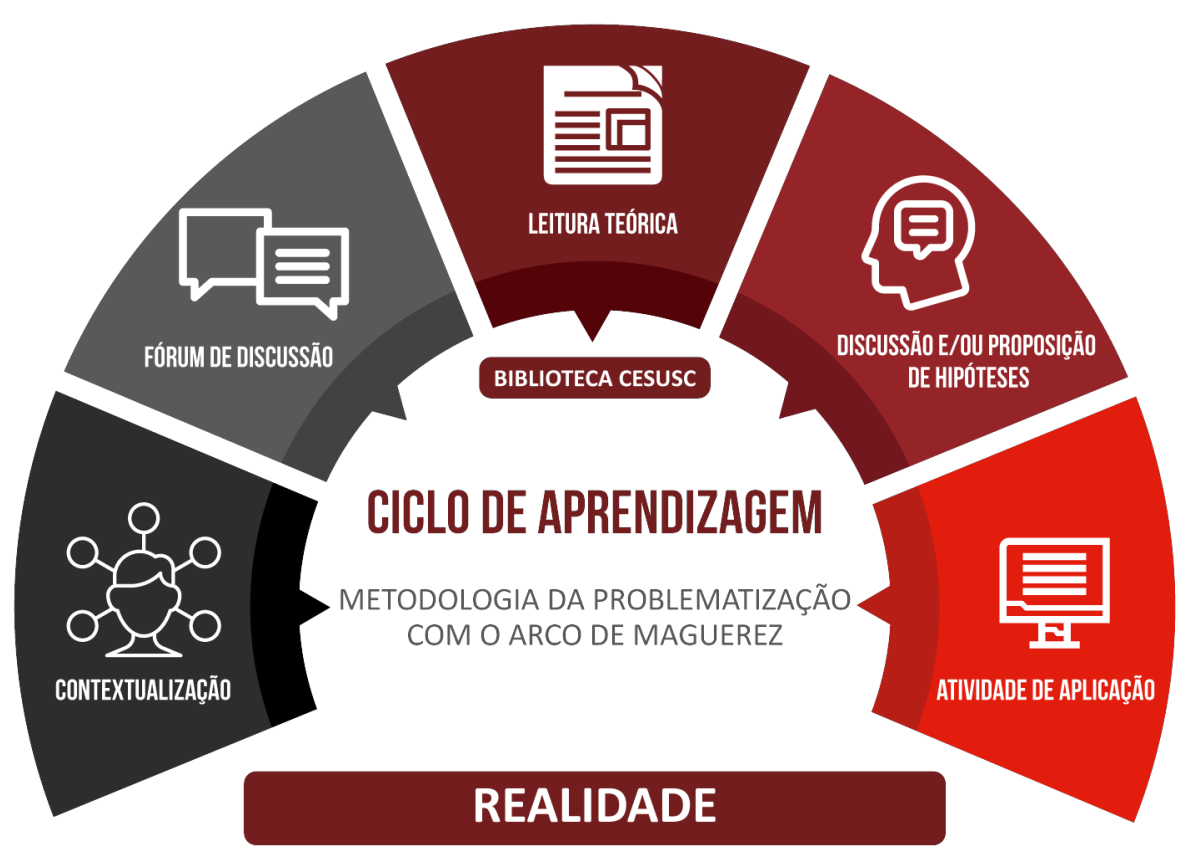


Figura: Arco de Maguerez Adaptado

Estas atividades são realizadas a partir de um roteiro de estudos estabelecidos para cada aula pelo professor autor. Em cada aula se propõe a realização de 5 (cinco momentos fundamentais), o primeiro momento previsto pelo roteiro de estudos é o de (1) contextualização e problematização do tema. Nesta primeira etapa o professor escolhe e disponibiliza aos estudantes um texto contextualizador a ser lido pelos estudantes que exponha um problema com potencial a ser explorado e solucionado pelo conteúdo da aula. No enunciado da atividade o professor orientará a leitura dos estudantes e poderá expor a questão problema a ser pensada e respondida ao final.

A contextualização dos problemas que cada aula debaterá servirá de ponto de partida para os estudantes. Neste momento o professor deverá instigar os alunos a debaterem sobre temas emergentes, temas de estudo contemporâneo ou mesmo históricos, de forma a balizar o início dos estudos, permitir compreender os conhecimentos dos estudantes sobre o tema, promover a interação entre estudantes e professores, avaliar os conhecimentos prévios de cada um sobre os assuntos e permitir a socialização dos conhecimentos sobre o tema e ainda prover a pesquisa inicial dos temas.

No momento seguinte (2) os estudantes são convidados a participar de um fórum assíncrono no AVA com o professor tutor. Neste fórum a proposta será a de discussão do texto apresentado na primeira etapa, de levantamento dos pontos principais abordados no texto e a de discutir possíveis soluções do problema levantado inicialmente. Nesta etapa busca-se propor a reflexão do problema específico de cada tema de estudo, o preparo para o estudo que se inicia, a troca e valorização de experiências e saberes entre estudantes, e a promoção do pensamento de pesquisa sistemático. Ao final, estudantes terão constituído um corpus inicial do que sabem sobre o assunto e um esboço de solução da questão problema.

A terceira etapa (3) será a de leitura teórica iniciada com explanação do professor autor sobre o livro a ser estudado, sobre o autor da obra e orientações de leitura. Neste momento o aluno realiza a leitura orientada dos textos originais elencados na bibliografia básica e, com apoio do professor tutor, buscará compreender os conteúdos, os conceitos e as relações entre o texto teórico, a realidade e o problema apresentado no início da aula.

Os professores se valerão de livros e artigos acadêmicos entre outros materiais de leituras. A ideia parte da busca pela promoção de diferentes fontes de leitura de forma a ampliar o leque de fontes de informações dos estudantes e mesmo a leitura comparativa e crítica dos materiais de leitura e de compreensão da realidade na sua complexidade de relações.

A leitura de livro texto e estudo teórico será promovia com o intuito de que o estudante 
tenha contato com diferentes linguagens, modos de escrita, de organização de pensamento, buscando a formação de uma prática de leitura plena por parte dos estudantes.

A busca principal neste tópico diz respeito à tradição universitária de leitura científica e com o mínimo de filtros, com a leitura do autor original sempre que possível. Isto não significa que os alunos terão que estudar por conta própria, a faculdade e seus professores têm resguardado seu papel de ensino, de mediação, de apoio ao estudo, mas acima de tudo busca-se a construção de estudantes leitores e produtores de conhecimentos, capazes de compreender e ler criticamente diferentes materiais.

Após este momento os estudantes são convidados a participar de um novo fórum assíncrono no AVA (4) com o professor tutor. Neste fórum a proposta será a de discussão do texto teórico apresentado, de levantamento dos conceitos principais, de confrontação com as soluções para o problema levantado inicialmente e a proposição de novas soluções com base na leitura, pesquisa e discussões. Nesta etapa busca-se novamente propor a reflexão do problema específico de cada tema de estudo, mas de forma balizada com fundamento de leitura e pesquisa. Ao final, estudantes são estimulados a constituir um corpus do que aprenderam sobre o assunto e hipóteses de solução do problema.

Novamente a atividade realizada em grupo permite a integração dos estudantes e a socialização de saberes entre a turma. O movimento de teorização a partir do problema em discussão e a proposta de diálogo entre alunos, professores e textos da literatura acadêmica resultam reflexões importantes que relacionam realidade dos discentes, os saberes acadêmicos e a produção de novos saberes e práticas.

No ponto de retorno à base realidade, a atividade do aluno se encaminha para a aplicação das soluções propostas (5). Do confronto entre a questão problema enunciada e sua contextualização, das experiências prévias dos estudantes, da teorização e das hipóteses propostas, os alunos realizam atividades de aplicabilidade com exercícios de estudo de caso, pesquisa de campo, produção de artigos e outras atividades previstas na política institucional da faculdade.

O resultado esperado será o de produção que envolve prática de pesquisa, apego à realidade, apego à cultura universitária e ao estudo teórico com fins à produção acadêmica de impacto.

No decorrer do processo os alunos passarão a entender que a produção científica se inicia com estudo, diálogo, com o aprendizado de teorias, métodos, conceitos, técnicas, regras, rigor e pensamento. Deste entendimento o Arco de Maguerez apoiará a estruturação de um modo de trabalho voltado à resolução de problemas contextualizados com a realidade dos alunos, ao respeito às suas vivências e saberes, ao estudo teórico balizado pela leitura de textos acadêmicos, e pelo direcionamento do professor tutor na busca de soluções aos problemas suscitados em cada aula de forma 
sistemática.

\section{Implantação da Metodologia da Problematização}

Com a implantação do NEAD, buscou-se a reestruturação do Cesusc Virtual e o início da implantação do Curso Tecnólogo de Gestão Comercial a distância. A partir desse período, definiu-se nova forma para a plataforma Cesusc Virtual, estudos para adaptação das salas de aula e até implantados diálogos com os docentes em torno de possibilidades educativas com uso mais intenso das Tecnologias da Informação e Comunicação (TIC's).

Também promoveram estudos para busca de melhores métodos e práticas de trabalho em Educação a Distância. Foram consideradas as especificidades da história da Faculdade Cesusc, da cultura de trabalho da Instituição e de sua comunidade, bem como das demandas da contemporaneidade. A partir dessa data passou-se a ofertar Cursos de Extensão, e o resultado dessas experiências ensejou o uso mais intenso da Plataforma Cesusc Virtual de forma madura por parte dos discentes e docentes e o ajuste de metodologias de trabalho, de ensino e aprendizagem.

Desses diálogos iniciou-se a proposta de realização da disciplina de Métodos e Técnicas de Pesquisa em Administração I, de forma semipresencial, no Curso de Administração. A disciplina da primeira fase foi desenvolvida para disseminar entre os alunos as práticas tecnológicas de estudo e novos formatos de aula; entre os professores a disciplina serviu de laboratório de estudos. De 2013 em diante, a disciplina foi desenvolvida de forma presencial e permitiu o uso do Cesusc Virtual por parte de todos os ingressantes do Curso de Administração, do começo ao fim do primeiro semestre do curso.

Com a remodelação do Cesusc Virtual, as disciplinas de Projeto e Trabalho de Conclusão de Curso dos Cursos de Administração e Direito ganharam um espaço melhor estruturado para realização de orientações e entrega de materiais, TCCs e projetos. Nesse período, buscaram-se melhores métodos de trabalho em Educação a Distância, e os resultados dessas experiências levaram ao uso mais intenso da Plataforma Cesusc Virtual na IES. Isso propiciou o ajuste de metodologias de trabalho de ensino e aprendizagem, que resultaram nos novos projetos apresentados a partir de 2013.

No ano de 2013, o novo modelo de estruturação da Plataforma Cesusc Virtual foi delineado e efetivado com a gradativa integração dos Cursos presenciais, no intuito de oferecer suporte tecnológico e didático aos professores e alunos.

No ano de 2014, chega-se a mais 300 (trezentos) estudantes atuando em disciplinas dos Cursos de Administração, Direito, Análise e Desenvolvimento de Sistemas, além dos Cursos de nivelamento de Língua Portuguesa promovidos pelo Núcleo de Apoio 
Psicopedagógico da Instituição.

Em 2015 são ofertadas as disciplinas de Projeto e Trabalho de Conclusão de Curso de Direito e Administração e as disciplinas de Projeto Integrador do Curso Superior de Tecnologia em Análise e Desenvolvimento de Sistemas, essa última perpassando todo o Curso.

O ambiente virtual da Faculdade também foi espaço destinado ao aprimoramento Docente, dos Colaboradores e de Cursos de Extensão para a Comunidade Acadêmica. Nesse período, foram realizados: o Curso de Aperfeiçoamento Acadêmico para os alunos das 3 (três) primeiras fases de todos os 5 (cinco) Cursos da Instituição; o desenvolvimento do ambiente de apoio da Central de Relacionamento e Atendimento da Instituição, Cursos referentes ao aprendizado sobre uso do Cesusc Virtual/Moodle aos docentes, além de Cursos para os professores autores e tutores dos futuros Cursos a Distância da Faculdade.

\section{Considerações finais}

Como resultados destacamos o caráter autônomo e experimental do projeto e sua execução. A metodologia da problematização é desenvolvida com o intuito de conectar estudantes e professores com as realidades de seus entornos de atuação, bem como com a noção de resolução de problemas reais e situações profissionais aplicadas. Do mesmo modo, pesquisas e teorias são pensadas enquanto suporte de apoio vivo para pensar as diferentes realidades e solucionar problemas.

Em alinhamento com a cultura da instituição e o entendimento próprio desenvolvimento e crescimento do projeto, bem como a estruturação do projeto EAD em torno da cultura da Instituição, sua relação com a sociedade e resultados de aprendizado dos estudantes.

\section{Referências}

BERBEL, N. A. N. Metodologia da problematização no ensino superior e sua contribuição para o plano da práxis. Semina: Ciências Sociais e Humanas, Londrina, v. 17, p. 7-17, 1996.

Metodologia da problematização: experiências com questões de ensino superior. Londrina: UEL, 1998a.

BORDENAVE, J. D.; PEREIRA, A. M. Estratégias de ensino aprendizagem. 4. ed. Petrópolis: Vozes, 1977. 
FACULDADE CESUSC. Plano de Gestão EAD. Florianópolis: Cesusc, 2015.

Projeto Pedagógico do Curso Superior de Tecnologia (CST) em Gestão Comercial. Florianópolis: Cesusc, 2015.

Projeto Pedagógico do Curso Superior de Tecnologia (CST) em Gestão Comercial. Florianópolis: Cesusc, 2017. 